\title{
The Textile Contribution to the World of Art
}

\section{Daniel Bilbao Peña*}

Departament of Drawing's, University of Seville, Spain

*Corresponding author: Daniel Bilbao Peña, Departament of Drawing's, Fine Arts Faculty, University of Seville, Spain

submission: 眥June 25, 2018 Published: 眥 August 01, 2018

\begin{abstract}
The textile contribution to the world of art and in particular to the painting sector was always enriching.

Object of study in all epochs, the artists have analyzed the fabrics, their folds, falls, shades, brightness and qualities. But not only did it serve as an inspiring motif, its qualities as a pictorial medium represented a technological advance due to its lightness and the extensive formats it allowed, unlike other bases such as wood which, due to its density and weight, was a limiting medium for large works of art.
\end{abstract}

\section{Development}

As for its appeal as clothing, it appears in artistic representations from the oldest civilizations showing both the beauty of color in the cloths and the social status of the characters represented, as can be seen in the paintings and frescoes of crete and Rome.

In the case of the Kore, female statues of young bidders, reach one of the highest levels in the conception of Art of the archaic period S. VIII-VI BC (Figure 1). Dressed in a simple and heavy tunic that allows the anatomy to be subtly perceived, it only marks the waist. The artist has learned to make the body notice under the austere simple surface. The thickness of the cloth determines the fall of the folds that at the lower edge appear meticulously worked and colored later with bright tones that in most cases have lost with the passage of time [1].

Figure 1: Kuros Greek art archaic period. 


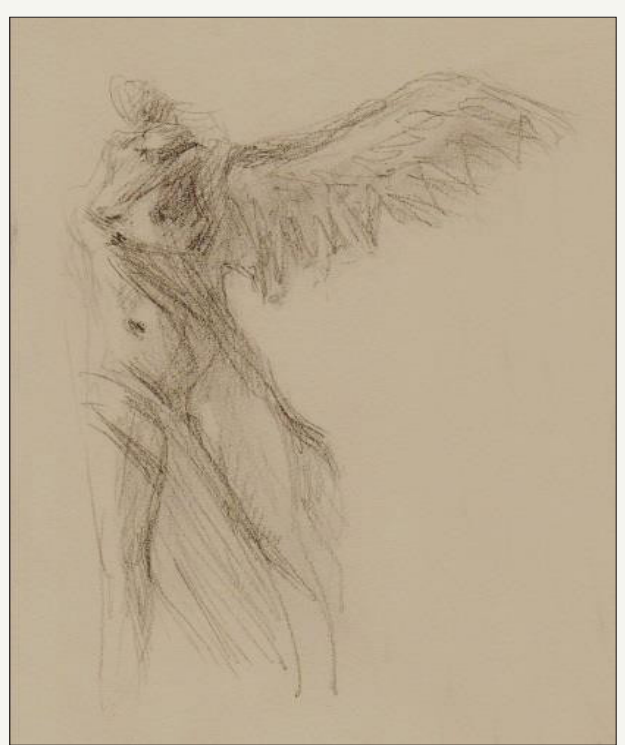

Figure 2: Victory of samothrace (Around $190 \mathrm{BC}$ ), Wet cloths technique attributed to the works of Phidias.

The sculpture also represents the tissues special attention and delicacy. The stiff and rough clothes in the first Greek sculptures, were evolving towards soft qualities that were sinuously adapted to the anatomy of the represented model. The technique of wet fabrics in classical Greece posed sculptures with the appearance of wet veils attached to the body thus allowing a perfect modeling of the Figure 2.

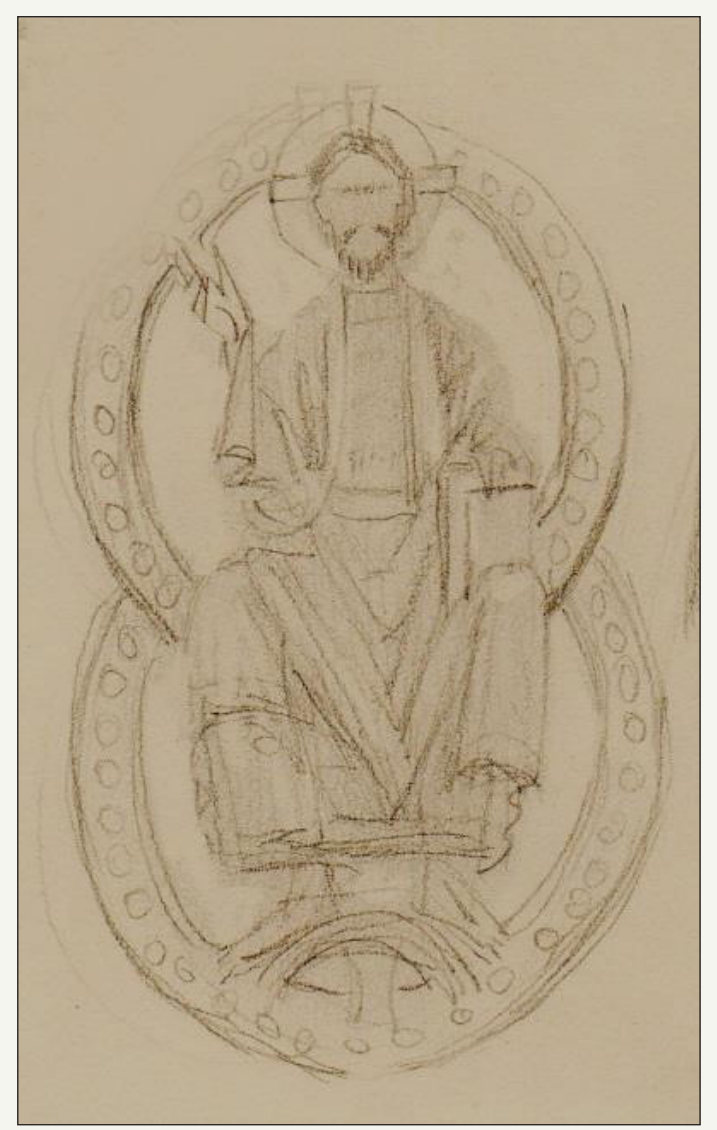

Figure 3: Front altar la seu d'urgell 'Maiestas Domini' (Christ in majesty), medieval Romanesque $12^{\text {th }}$ century Spanish.

In the low average age the fabrics of the clothes were treated as rhythmic syntheses with rounded proportions adapted to a proportion according to the scales of the churches of the moment (Figure 3). 
This language typical of the romanesque later evolves into the gothic where the cloths represented in both paintings and sculptures are stylized accompanying the rhythmic verticality that marks the architectural ogive. The search for the divine and its conceptual representation of the ascendant make the represented fabrics acquire a mystical elegance (Figure 4).

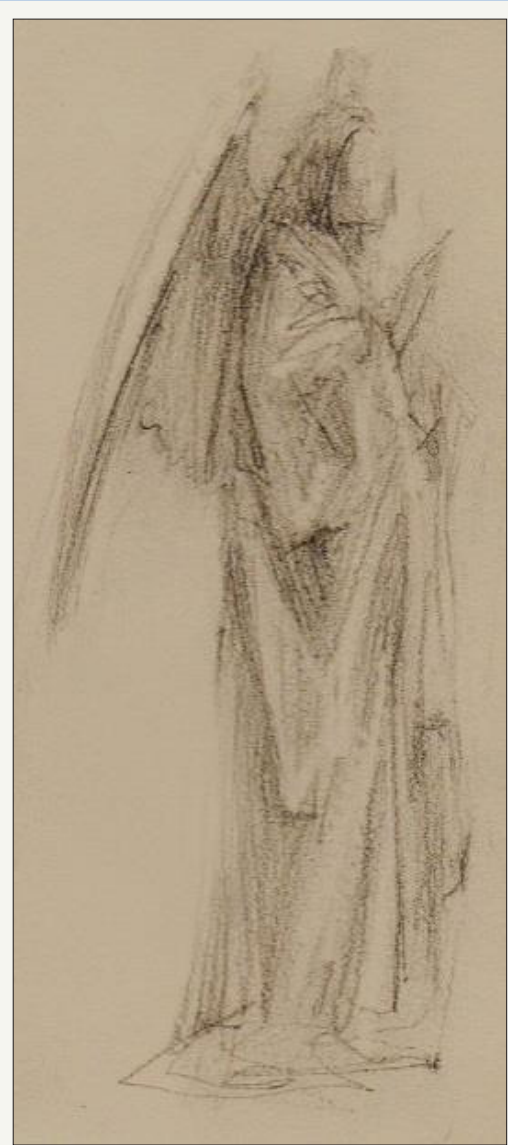

Figure 4: Jan van eyck archangel saint gabriel.

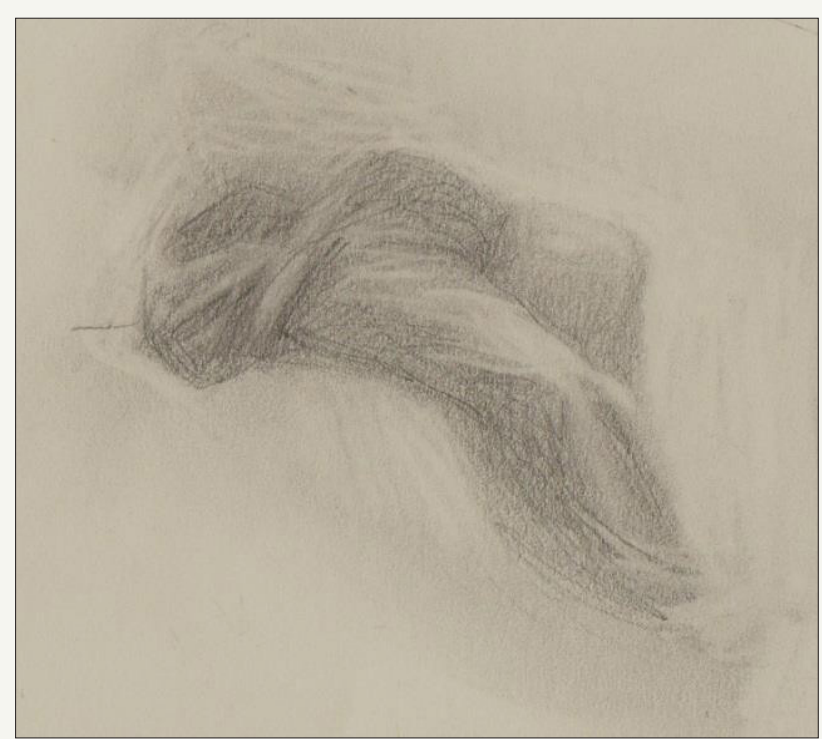

Figure 5: Leonardo da vinci 1508 clothes study.

The movement of the historical pendulum will contrast Renaissance dynamism to the clothes shaking off the corsets of the middle ages, timidly at first with the pictorial representations of
Giotto, to evolve into Leonardo Da Vinci's studies of clothing (Figure $5)$. 
In the Baroque, the most dynamic forms in tissue representations are reached, such as the expressive Ecstasy of Saint Teresa of Bernini, a sculptural ensemble that achieves a surprising technical splendor in the treatment of the folds of the mystic's clothing (Figure 6).

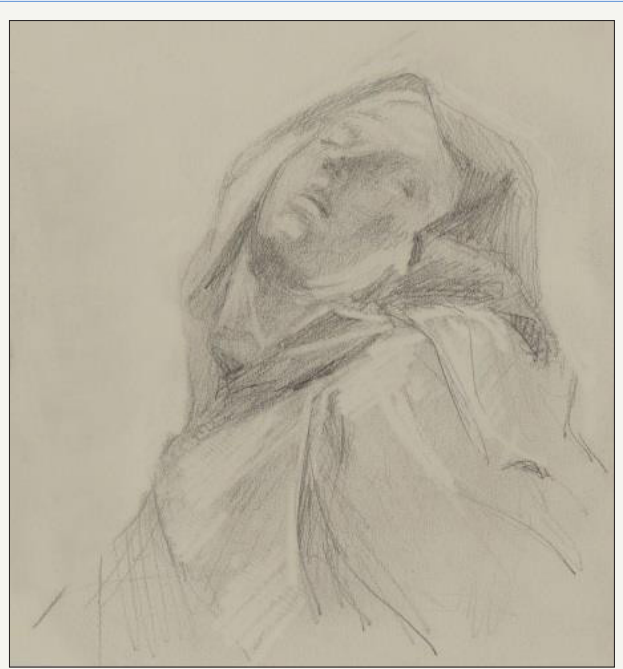

Figure 6: Ecstasy of santa teresa gian lorenzo bernini $17^{\text {th }}$ century.

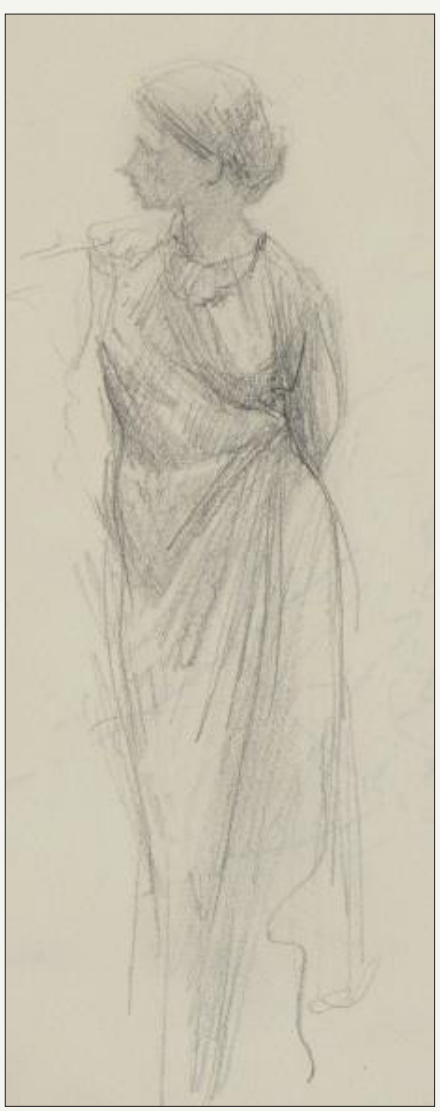

Figure 7: Albert joseph moore (1841-1893) classicism.

In the neoclassical period the fabrics tend to be appeased again and show more anatomy as the humanist canons of Greece and Rome are again the inspiring references of this era. Romanticism turns its gaze to the exotic in search of new frontiers and emotions, so that the fabrics of the represented clothes will be impregnated with orientalisms, silk shines and new colors of Indian influence.
In this stage it is remarkable the design of clothes that appear in the paintings of the british albert moore or the spanish fortuny, also the viennese cesseción and with gustav klimt who contributes a personal vision of fabrics and clothes with a sensuality and treatment of the qualities that integrate the exotic with the new forms of judenstill (Figure 7). 
The traffic of the nineteenth to the twentieth century triggers a whirlwind of artistic movements that will be combined in what will be called first avant-garde. This tumultuous amalgam will result in new conceptions and plastic languages, its greatest contribution being the discovery of abstraction as a concept and form. The contribution of Sonia Delaunay, who directed her pictorial work to the design of fabrics based on abstract forms, generally composed of concentric rhythms and bright colors, is relevant at this time. This opening to abstraction will provide new codes that continue to this day (Figure 8).

Figure 8: $20^{\text {th }}$ century sonya delaunay -Portait.

The other facet of the fabric that we enumerated in the beginning of the article, that is to say, as support of the picture, supposed a relevant technological advance in the world of the painting. Although there are data on the use of cloths in Egypt attached to papyri and in ancient Greece, pasted on wood, it is not until the fifteenth century when it acquired identity as an independent support.

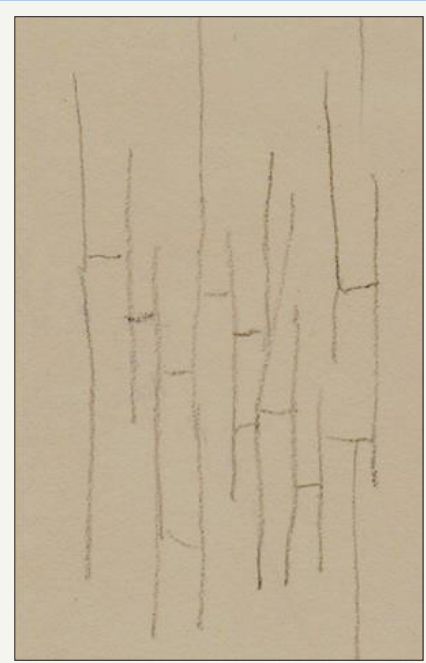

Figure 9: Diagram of the natural craquelure of the painter on wood. 
The paint on canvas (Figure 9), requires a previous primer to paint on it in a traditional way. This primer consists of a preparation that can vary according to each artist, its dual function is to protect the fabric from the direct action of the pigments on it.

The traditional formulas have been transmitted and some of them are collected in treaties about painting at different times. One of the most reputable contemporary publications due to its scientific nature is that of Professor Max Doerner [2].

One of the appreciable characteristics in the pictorial supports are the cracks that these affect the painted surface. The traditional painting on a wooden support usually needed to assemble planks to achieve a surface of considerable length. The most unfavorable mayor of the wood the weight that these works acquired in addition to the cracks that caused the assemblies and the own fiber of the support. The cracks that appear in the paintings with this type of base is longitudinal, along the natural fiber of the wood. Image 9 The fabric provides lightness, as mentioned previously, unusual until then and a larger pictorial surface. The movements of dilation and contraction caused by the fabrics will depend on their hydrophilic capacity. Therefore, linen is considered one of the best fibers for canvas, since it is more stable than others such as cotton. The cracks that can be seen on the surface of a painting made on canvas will be epicentric and in the form of "spider web" (Figure 10).

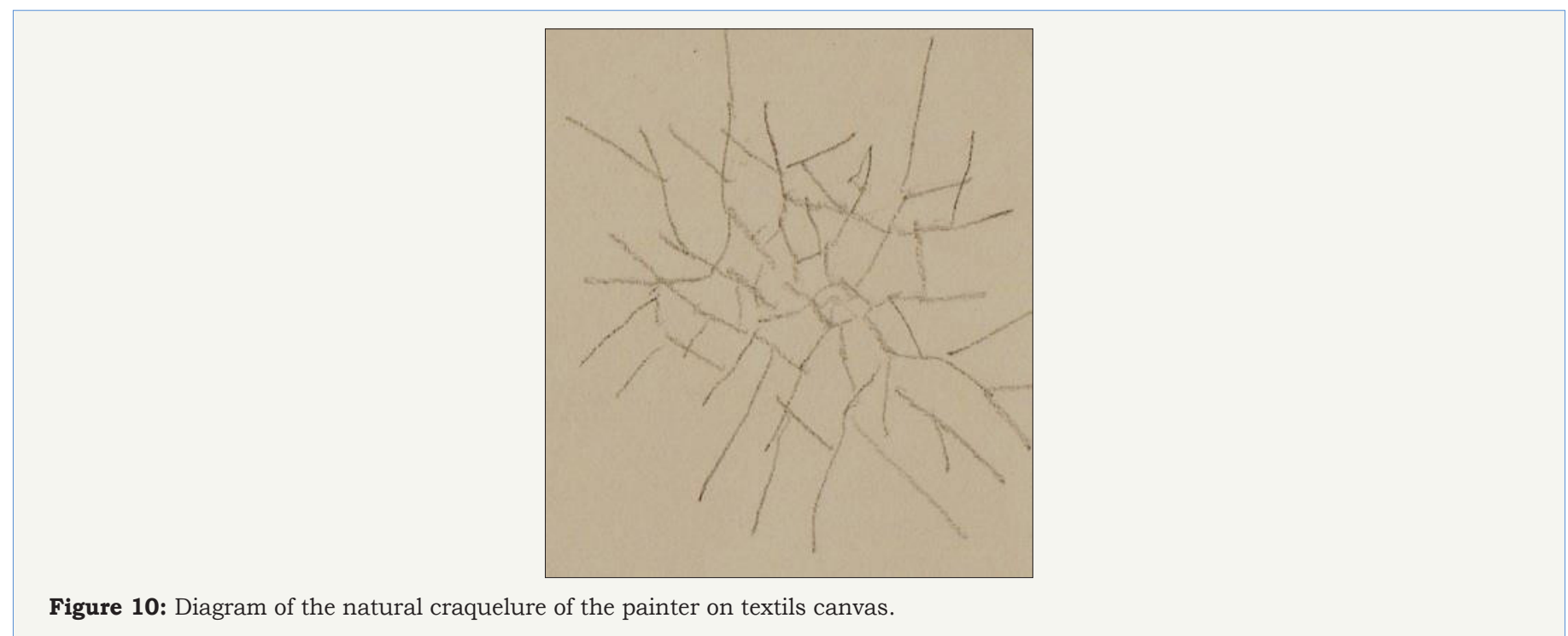

\section{References}

1. http://www.historiadelarte.us/arte-griego/kore-de-peplo/

2. Doerner M (1998) Painting materials and their use in art ( $6^{\text {th }}$ edn).

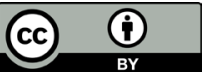

Creative Commons Attribution 4.0 International License

For possible submissions Click Here

\section{Submit Article}

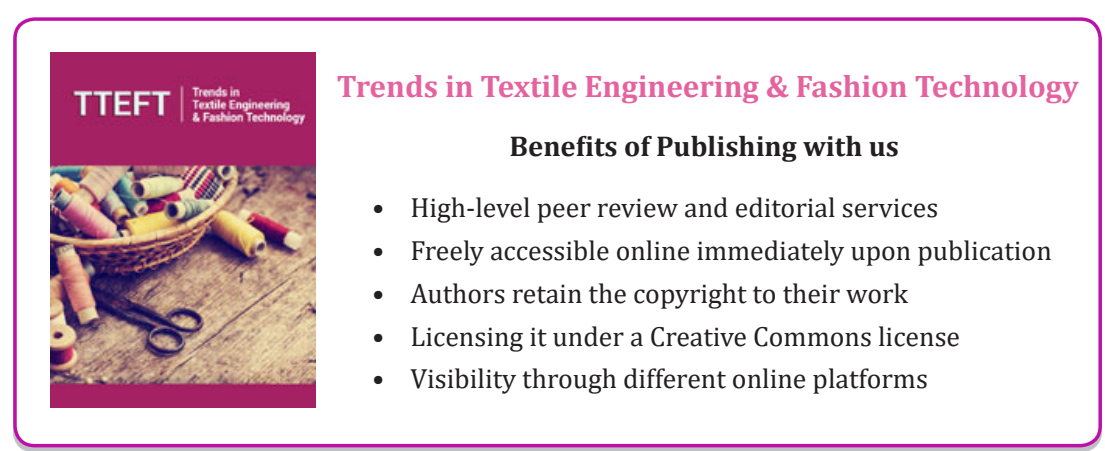

